\title{
Dynamic behaviour of a planetary reducer with double planet gears
}

\author{
Milos S. Matejic ${ }^{1}$, Mirko Z. Blagojevic ${ }^{1}$, and Marija M. Matejic ${ }^{2}$ \\ ${ }^{1}$ University of Kragujevac, Faculty of Engineering, Sestre Janjic 6, Kragujevac, 34000, Serbia \\ ${ }^{2}$ University of Priština temporarily settled in Kosovska Mitrovica, Faculty of Technical Sciences, Knjaza \\ Milosa 7, Kosovska Mitrovica, 38220 \\ Correspondence: Milos S. Matejic (mmatejic@kg.ac.rs)
}

Received: 25 August 2021 - Revised: 4 October 2021 - Accepted: 16 October 2021 - Published: 17 November 2021

\begin{abstract}
Planetary reducers have a wide and significant application in modern machine industry. They are extremely compact and reliable, and they can achieve a wide range of gear ratios as well as high efficiency. Since they often operate in extremely changeable working conditions, such as often starting and stoping, it is both interesting and desirable to study their dynamic behaviour. This paper presents a dynamic model of a planetary reducer with double planet gears created by applying Lagrange's equations of the second kind. After a planetary gear reducer has been designed and a CAD model created, the dynamic model was made. Most of characteristic values needed for solution of the equations are taken from the CAD model. Due to their complexity, the equations are solved in math simulation software. A lot of interesting results concerning the dynamic behaviour of the model are obtained, which can be helpful in understanding the dynamic occurrences in the inside of a planetary gearbox. At the end of the paper, conclusions are drawn, and further research directions in this area are given.
\end{abstract}

\section{Introduction}

Planetary reducers are widely used in mobile machine drive systems due to their compact design. Operating conditions for power transmissions with planetary reducers are variable within wide application limits. The research area of planetary reducer dynamics is of great importance. Examining the dynamics of those reducer types leads to conclusions that could greatly assist the development of planetary reducers with regard to increasing their compact design, increasing reliability, increasing the lifetime of reducer, reducing vibration and noise in working conditions, etc. Classical types of planetary gears have been well studied in the literature, but for some special types like planetary reducers with double planet gears and movable output ring gear, there are not a lot of published papers.

The interesting field of planetary reducers research before dynamics is kinematic analysis. Kinematic analysis is interesting from many aspects, but the main one is planetary reducer application in multiple transmission ratios usage. This application of the common planetary reducer concept used in multiple transmissions is described in papers which deal with the design and kinematic analysis of compound planetary gears (Troha et al., 2012; Karaivanov et al., 2012). That research is extended in order to show all shifting possibilities of the previously presented concept (Troha et al., 2014). Since in mobile machines gear trains operate in highly changeable working conditions, the analysis of the gear train dynamic behaviour is very significant. Studies of dynamic behaviour of planetary gear trains yield very important conclusions that contribute to the advancement of planetary gear trains by increasing design compactness, operation reliability, service life and efficiency or by reducing noise levels, gear train vibrations, etc. A dynamic model of a double-helical planetary gear train and its theoretical analysis is shown in the paper by Sondkar and Kahraman (2013). The experimental analysis of the double-helical planetary gear, with certain simplifications due to experimental constraints, is presented in Kang and Kahraman (2015). In the available literature, there are a lot of detailed studies on how dynamic stability of planetary gear reducers is affected by manufacturing error of the planetary reducer elements, tooth profile modifications, stiffness 
(a)

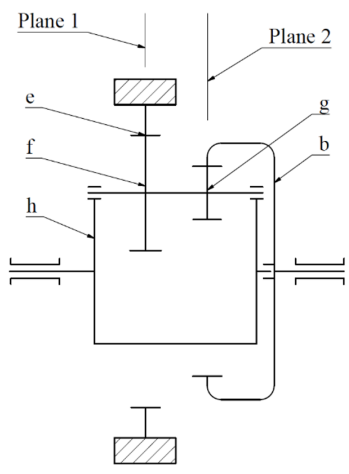

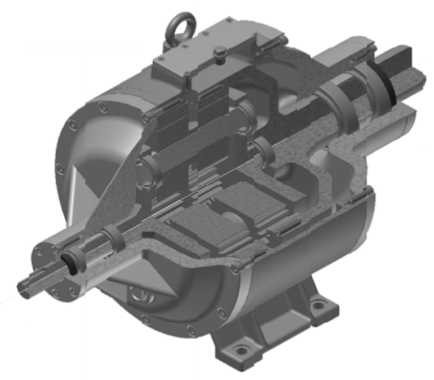

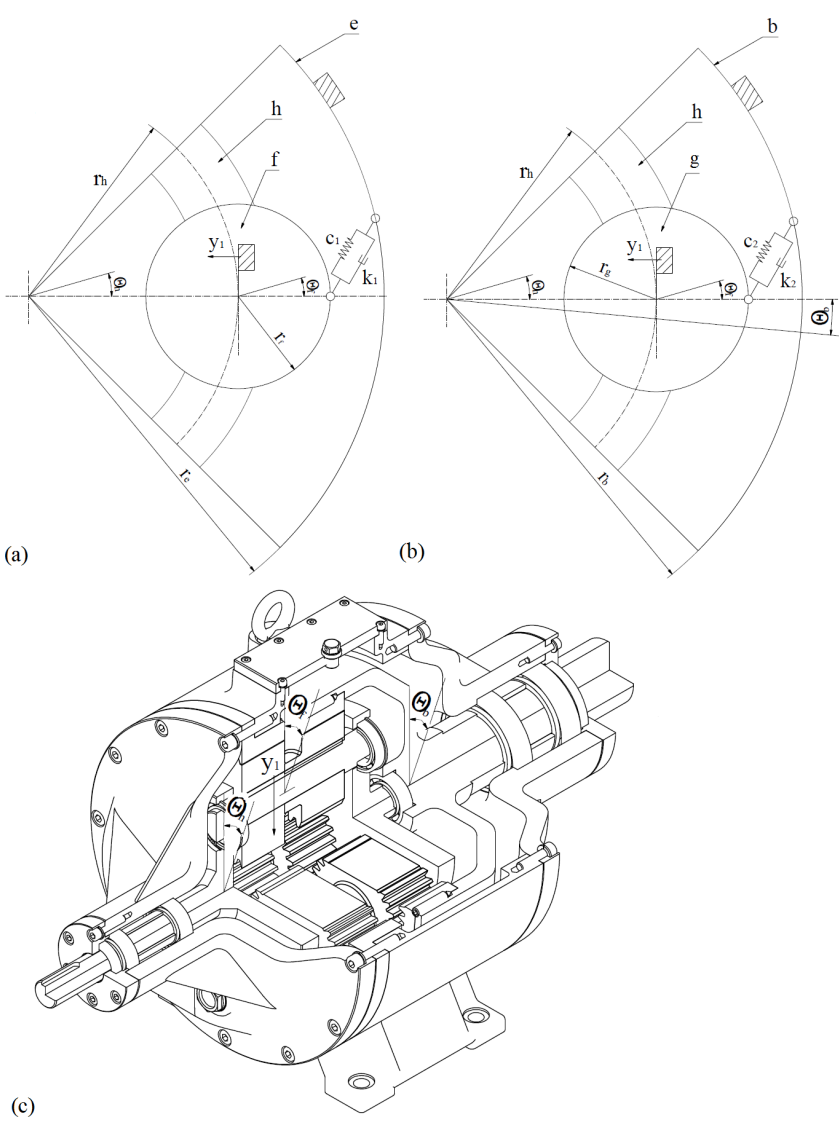

Figure 2. Dynamic model of the planetary reducer with double planet gears: (a) plane 1; (b) plane 2; (c) three-dimensional dynamic model.

have the double planet gears. The presented dynamic model is based on the previously designed CAD model. The paper concludes with direct points which can be used as a general rule for this type of planet gears and shows the future direction of the research. The presented papers can be used as guidelines for further investigation of aspects of this reducer type, as well as in the design process, considering the vibration in start-stop reducer mode.

\section{Basic assumptions of the dynamic model}

Before dynamic analysis is conducted, the basic assumptions have to be made. Figure 1 shows the planetary reducer studied in this paper. It is a two-stage planetary reducer with double planet gears, where the first ring gear is stationary (ring gear e), while the second ring gear is movable (ring gear b). The chosen reducer has three planet gears. two papers from all discussed papers deal with planetary reducers with double planet gears, so the lack of data in that field is evident. This paper presents a dynamic model of a planetary reducer with double planet gears, in which the first ring gear is stationary while the second one revolves around its own axis. This paper should help in better understanding the dynamic occurrences in the planetary reducers which 


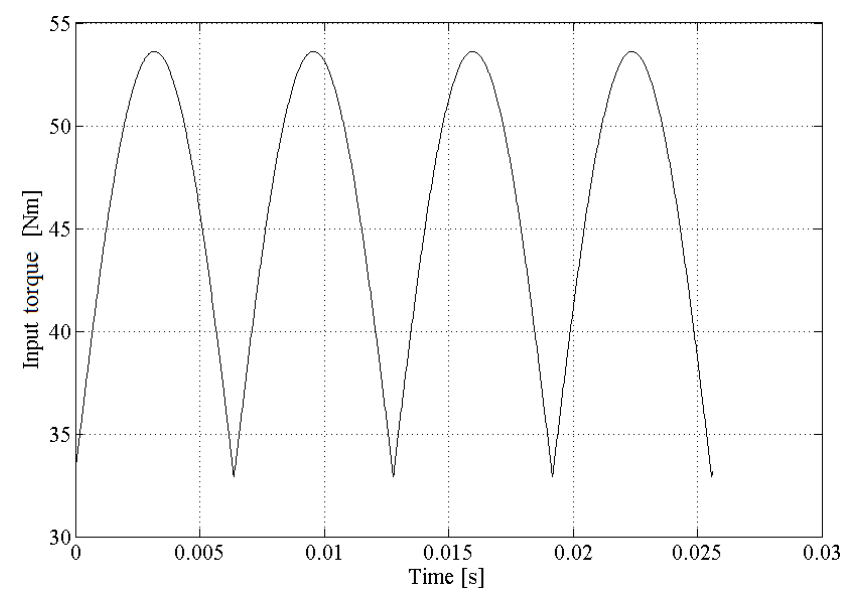

Figure 3. Input torque.

The dynamic model of the planetary gear train is defined after the gear train has been observed in two planes (Fig. 1a). Based on the degrees of freedom of the gear reducer, the displacement directions of the dynamical model are determined. Each displacement is presented by the real direction and orientation that occur during the operation of the gear reducer. The pulsating input torque is transferred from the planet gear carrier to the planet gears and then from the planet gears to the movable and the stationary ring gears. The model has 4 degrees of displacement freedom: $y_{1}$ - displacement of the satellite and the double planet gears in the radial direction, $\theta_{\mathrm{h}}$ - angular displacement of the planet carrier around its own axis, $\theta_{\mathrm{f}}-$ angular displacement of the planet gears $\mathrm{f}-\mathrm{g}$ around its own axis, and $\theta_{\mathrm{b}}$ - angular displacement of the movable ring gear round its own axis.

The following contacts between the mashed gear teeth are modelled using the suitable springs and dampers: the contact between the gear e and the gear $\mathrm{f}$ (the spring stiffness $c_{1}$ and the damper with the damping coefficient $k_{1}$ ) and the contact between the gear $\mathrm{g}$ and the gear $\mathrm{b}$ (the spring stiffness $c_{2}$ and the damper with the damping coefficient $k_{2}$ ). The degrees of displacement freedom and the defined meshes are presented in Fig. 2.

In order to obtain as many accurate results as possible, the total masses of the system elements are taken into account (not the reduced ones). The total masses of the parts and the moments of inertia are obtained from the CAD model, which makes the solution to these equations even more correct.

The dynamical model is defined using Lagrange's equations of the second kind, assuming the displacement $y_{1}$ to be collinear with the angular displacements but in the opposite direction.
Lagrange's equations of the second kind have the following general form as given in Eq. (1):

$$
\frac{d}{\mathrm{~d} t} \frac{\partial E_{\mathrm{k}}}{\partial \dot{q}_{i}}-\frac{\partial E_{\mathrm{k}}}{\partial q_{i}}=-\frac{\partial E_{\mathrm{p}}}{\partial q_{i}}-\frac{\partial \phi}{\partial \dot{q}_{i}}+Q_{i},
$$

where $E_{\mathrm{k}}$ is kinetic energy, $E_{\mathrm{p}}$ is potential energy, $\Phi$ is the dissipation function, $q_{i}$ represents the generalized coordinates, and $Q_{i}$ represents the conservative forces.

In matrix form, Lagrange's equations of the second kind are as given in Eq. (2):

$\{M\}\{\ddot{q}\}+B\{\dot{q}\}+C\{q\}=D$,

where $M$ is the mass matrix, $B$ is the damping matrix, $C$ is the stiffness matrix, $\{D\}$ is the generalized forces vector, $\{\ddot{q}\}$ is the generalized accelerations vector, $\{\dot{q}\}$ is the generalized velocities vector, and $\{q\}$ is the generalized displacements vector.

\section{Dynamic model of the planetary reducer with double planet gears}

The kinetic energy of the gear reducer is calculated as the sum of kinetic energies of the gear reducer elements. The total kinetic energy is given with Eq. (3):

$$
\begin{aligned}
& E_{\mathrm{k}}=\frac{1}{2}\left[m_{\mathrm{h}}\left(\dot{y}_{1}^{2}+r_{\mathrm{h}}^{2} \dot{\theta}_{\mathrm{h}}^{2}\right)+J_{\mathrm{ch}} \dot{\theta}_{\mathrm{h}}^{2}\right]+\frac{1}{2}\left[m_{\mathrm{f}}\left(\dot{y}_{1}^{2}+r_{\mathrm{h}}^{2} \dot{\theta}_{\mathrm{h}}^{2}\right)\right. \\
& \left.+J_{\mathrm{cf}}\left(\dot{\theta}_{\mathrm{h}}+\dot{\theta}_{\mathrm{f}}\right)^{2}\right]+\frac{1}{2}\left[m_{\mathrm{g}}\left(\dot{y}_{1}^{2}+r_{\mathrm{h}}^{2} \dot{\theta}_{\mathrm{h}}^{2}\right)+J_{\mathrm{cg}}\left(\dot{\theta}_{\mathrm{h}}+\dot{\theta}_{\mathrm{f}}\right)^{2}\right] \\
& +\frac{1}{2} J_{\mathrm{cb}} \dot{\theta}_{\mathrm{b}}^{2}
\end{aligned}
$$

The potential energy of the gear reducer is given in Eq. (4):

$$
\begin{aligned}
& E_{\mathrm{p}}=\frac{1}{2} c_{1}\left\{y_{1}^{2}+\left[r_{\mathrm{f}}\left(\theta_{\mathrm{h}}+\theta_{\mathrm{f}}\right)+r_{\mathrm{h}} \theta_{\mathrm{h}}\right]^{2}\right\}-c_{1} y_{1}\left[r_{\mathrm{f}}\left(\theta_{\mathrm{h}}+\theta_{\mathrm{f}}\right)\right. \\
& \left.+r_{\mathrm{h}} \theta_{\mathrm{h}}\right]+\frac{1}{2} c_{2}\left\{y_{1}^{2}+\left[r_{\mathrm{g}}\left(\theta_{\mathrm{h}}+\theta_{\mathrm{f}}\right)+r_{\mathrm{h}} \theta_{\mathrm{h}}-r_{\mathrm{b}} \theta_{\mathrm{b}}\right]^{2}\right\} \\
& -c_{2} y_{1}\left[r_{\mathrm{g}}\left(\theta_{\mathrm{h}}+\theta_{\mathrm{f}}\right)+r_{\mathrm{h}} \theta_{\mathrm{h}}-r_{\mathrm{b}} \theta_{\mathrm{b}}\right] .
\end{aligned}
$$

The dissipation function is given in Eq. (5):

$$
\begin{aligned}
& \phi=\frac{1}{2} k_{1}\left\{\dot{y_{1}^{2}}+\left[r_{\mathrm{f}}\left(\dot{\theta_{\mathrm{h}}}+\dot{\theta}_{\mathrm{f}}\right)+r_{\mathrm{h}} \dot{\theta}_{\mathrm{h}}\right]^{2}\right\}-k_{1} \dot{y}_{1}\left[r_{\mathrm{f}}\left(\dot{\theta_{\mathrm{h}}}+\dot{\theta}_{\mathrm{f}}\right)\right. \\
& \left.+r_{\mathrm{h}} \dot{\theta}_{\mathrm{h}}\right]+\frac{1}{2} k_{2}\left\{\dot{y_{1}^{2}}+\left[r_{\mathrm{g}}\left(\dot{\theta_{\mathrm{h}}}+\dot{\theta}_{\mathrm{f}}\right)+r_{\mathrm{h}} \dot{\theta}_{\mathrm{h}}-r_{\mathrm{b}} \dot{\theta}_{\mathrm{b}}\right]^{2}\right\} \\
& -k_{2} \dot{y_{1}}\left[r_{\mathrm{g}}\left(\dot{\theta}_{\mathrm{h}}+\dot{\theta}_{\mathrm{f}}\right)+r_{\mathrm{h}} \dot{\theta_{\mathrm{h}}}-r_{\mathrm{b}} \dot{\theta}_{\mathrm{b}}\right] .
\end{aligned}
$$


(a)

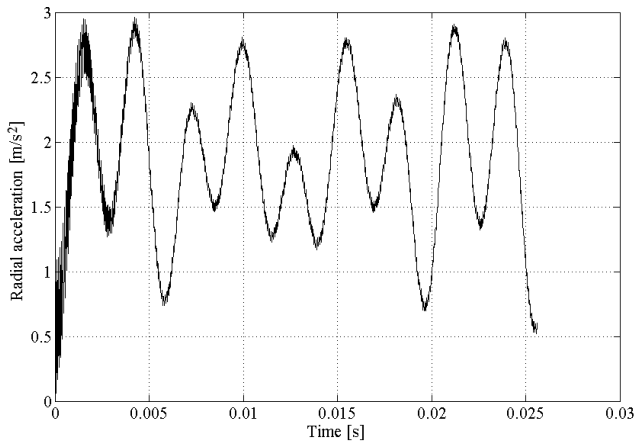

(c)

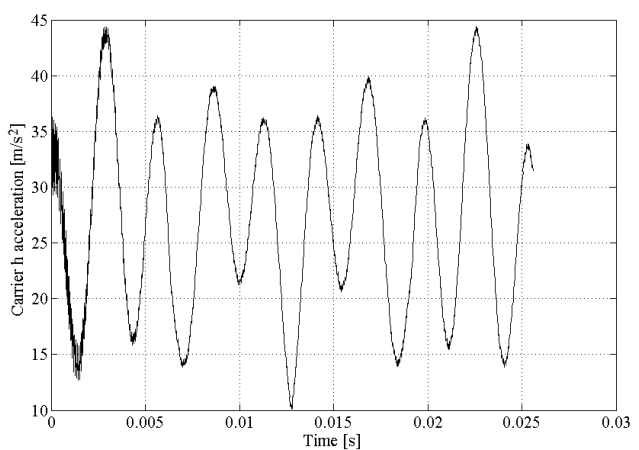

(b)

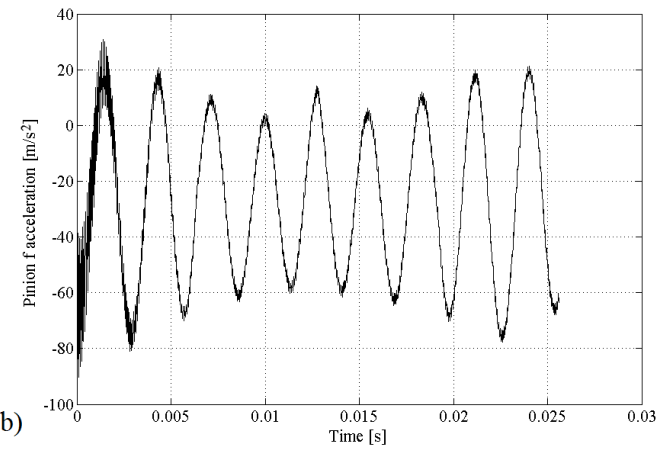

(d)

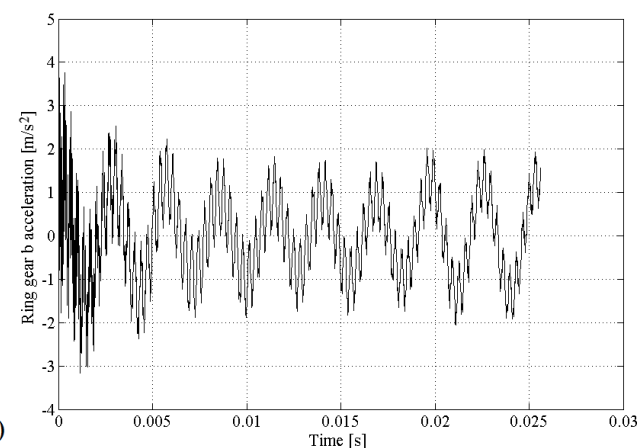

Figure 4. Acceleration diagrams for $c_{1}=1.67 \times 10^{10} \mathrm{~N} \mathrm{~m}^{-1}, c_{2}=1.56 \times 10^{10} \mathrm{~N} \mathrm{~m}^{-1}, k_{1}=3200 \mathrm{~N} \mathrm{~s} \mathrm{~m}^{-1}$, and $k_{2}=2400 \mathrm{~N} \mathrm{~s} \mathrm{~m}^{-1}$ : (a) $y_{1}$ direction, (b) $\theta_{\mathbf{h}}$ direction, (c) $\theta_{\mathrm{f}}$ direction, and (d) $\theta_{\mathbf{b}}$ direction.

(a)

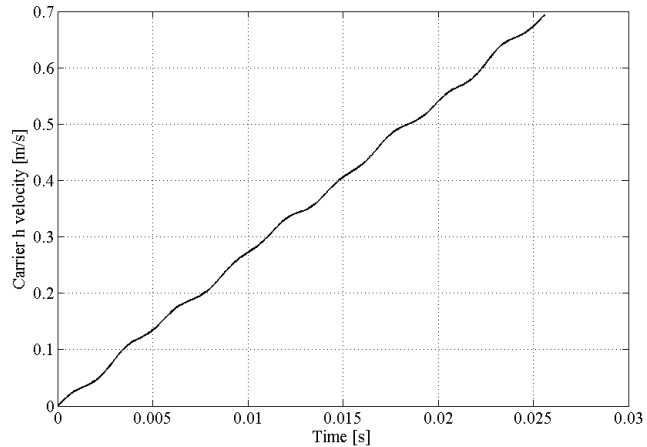

(c)

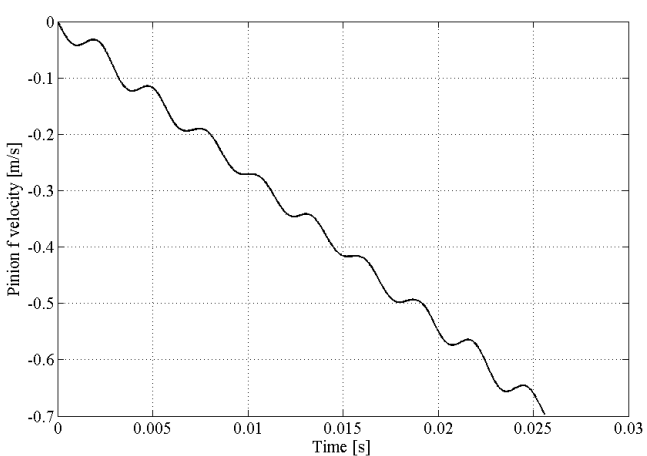

(b)

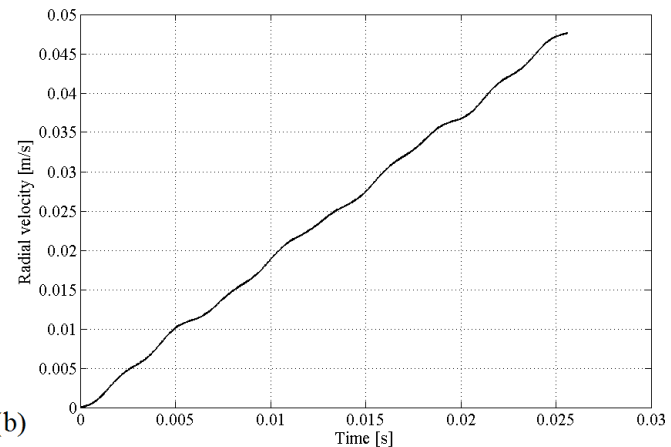

(d)

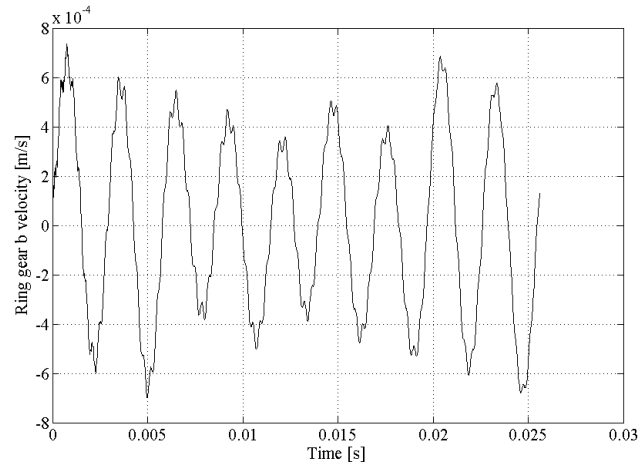

Figure 5. Velocity diagrams for $c_{1}=1.67 \times 10^{10} \mathrm{Nm}^{-1}, c_{2}=1.56 \times 10^{10} \mathrm{Nm}^{-1}, k_{1}=3200 \mathrm{~N} \mathrm{~s} \mathrm{~m}^{-1}$, and $k_{2}=2400 \mathrm{~N} \mathrm{sm}^{-1}:\left(\right.$ a) $y_{1}$ direction, (b) $\theta_{\mathrm{h}}$ direction, (c) $\theta_{\mathrm{f}}$ direction, and (d) $\theta_{\mathrm{b}}$ direction. 
Substituting the corresponding expressions, we get the motion equations of the system in Eqs. (6-9):

$$
\begin{aligned}
& \ddot{y}_{1}\left(m_{\mathrm{h}}+m_{\mathrm{f}}+m_{\mathrm{g}}\right)+y_{1}\left(c_{1}+c_{2}\right)-c_{1}\left[r_{\mathrm{f}}\left(\theta_{\mathrm{h}}+\theta_{\mathrm{f}}\right)+r_{\mathrm{h}} \theta_{\mathrm{h}}\right] \\
& -c_{2}\left[r_{\mathrm{g}}\left(\theta_{\mathrm{h}}+\theta_{\mathrm{f}}\right)+r_{\mathrm{h}} \theta_{\mathrm{h}}-r_{\mathrm{b}} \theta_{\mathrm{b}}\right]+\dot{y}_{1}\left(k_{1}+k_{2}\right) \\
& -k_{1}\left[r_{\mathrm{f}}\left(\dot{\theta}_{\mathrm{h}}+\dot{\theta}_{\mathrm{f}}\right)+r_{\mathrm{h}} \dot{\theta}_{\mathrm{h}}\right] \\
& -k_{2}\left[r_{\mathrm{g}}\left(\dot{\theta}_{\mathrm{h}}+\dot{\theta}_{\mathrm{f}}\right)+r_{\mathrm{h}} \dot{\theta}_{\mathrm{h}}-r_{\mathrm{b}} \dot{\theta}_{\mathrm{b}}\right]=0, \\
& \left(m_{\mathrm{h}} r_{\mathrm{h}}^{2}+J_{\mathrm{ch}}+m_{\mathrm{f}} r_{\mathrm{h}}^{2}+J_{\mathrm{cf}}+m_{\mathrm{g}} r_{\mathrm{h}}^{2}+J_{\mathrm{cg}}\right) \ddot{\theta}_{\mathrm{h}}+\left(J_{\mathrm{cf}}+J_{\mathrm{cg}}\right) \ddot{\theta}_{\mathrm{f}} \\
& +c_{1}\left[\theta_{\mathrm{h}}\left(r_{\mathrm{f}}+r_{\mathrm{h}}\right)+r_{\mathrm{f}} \theta_{\mathrm{f}}\right]\left(r_{\mathrm{f}}+r_{\mathrm{h}}\right)-c_{1} y_{1}\left(r_{\mathrm{f}}+r_{\mathrm{h}}\right) \\
& +c_{2}\left[\theta_{\mathrm{h}}\left(r_{\mathrm{g}}+r_{\mathrm{h}}\right)+r_{\mathrm{g}} \theta_{\mathrm{f}}-r_{\mathrm{b}} \theta_{\mathrm{b}}\right]\left(r_{\mathrm{g}}+r_{\mathrm{h}}\right) \\
& -c_{2} y_{1}\left(r_{\mathrm{g}}+r_{\mathrm{h}}\right)+k_{1}\left[\dot{\theta}_{\mathrm{h}}\left(r_{\mathrm{f}}+r_{\mathrm{h}}\right)+r_{\mathrm{f}} \dot{\theta}_{\mathrm{f}}\right]\left(r_{\mathrm{f}}+r_{\mathrm{h}}\right) \\
& -k_{1} \dot{y_{1}}\left(r_{\mathrm{f}}+r_{\mathrm{h}}\right)+k_{2}\left[\dot{\theta}_{\mathrm{h}}\left(r_{\mathrm{g}}+r_{\mathrm{h}}\right)\right. \\
& \left.+r_{\mathrm{g}} \dot{\theta}_{\mathrm{f}}-r_{\mathrm{b}} \dot{\theta}_{\mathrm{b}}\right]\left(r_{\mathrm{g}}+r_{\mathrm{h}}\right)-k_{2} \dot{y_{1}}\left(r_{\mathrm{g}}+r_{\mathrm{h}}\right)=M_{\mathrm{h}}, \\
& \left(J_{\mathrm{cf}}+J_{\mathrm{cg}}\right) \ddot{\theta}_{\mathrm{f}}+\left(J_{\mathrm{cf}}+J_{\mathrm{cg}}\right) \ddot{\theta}_{\mathrm{h}}+c_{1}\left[r_{\mathrm{f}}\left(\theta_{\mathrm{h}}+\theta_{\mathrm{f}}\right)+r_{\mathrm{h}} \theta_{\mathrm{h}}\right] r_{\mathrm{f}} \\
& -c_{1} y_{1} r_{\mathrm{f}}+c_{2}\left[r_{\mathrm{g}}\left(\theta_{\mathrm{h}}+\theta_{\mathrm{f}}\right)+r_{\mathrm{h}} \theta_{\mathrm{h}}-r_{\mathrm{b}} \theta_{\mathrm{b}}\right] r_{\mathrm{g}}-c_{2} y_{1} r_{\mathrm{g}} \\
& +r_{\mathrm{g}} k_{1}\left[r_{\mathrm{f}}\left(\dot{\theta}_{\mathrm{h}}+\dot{\theta}_{\mathrm{f}}\right)+r_{\mathrm{h}} \dot{\theta}_{\mathrm{h}}\right] r_{\mathrm{f}}-k_{1} \dot{y_{1}} r_{\mathrm{f}}+k_{2}\left[r_{\mathrm{g}}\left(\dot{\theta_{\mathrm{h}}}+\dot{\theta}_{\mathrm{f}}\right)\right. \\
& \left.+r_{\mathrm{h}} \dot{\theta}_{\mathrm{h}}-r_{\mathrm{b}} \dot{\theta}_{\mathrm{b}}\right] r_{\mathrm{g}}-k_{2} \dot{y_{1}} r_{\mathrm{g}}=0, \\
& J_{\mathrm{cb}} \ddot{\theta}_{\mathrm{b}}-c_{2} r_{\mathrm{b}}\left[r_{\mathrm{g}}\left(\theta_{\mathrm{h}}+\theta_{\mathrm{f}}\right)+r_{\mathrm{h}} \theta_{\mathrm{h}}-r_{\mathrm{b}} \theta_{\mathrm{b}}\right]+c_{2} y_{1} r_{\mathrm{b}} \\
& -k_{2} r_{\mathrm{b}}\left[r_{\mathrm{g}}\left(\dot{\theta_{\mathrm{h}}}+\dot{\theta}_{\mathrm{f}}\right)+r_{\mathrm{h}} \dot{\theta_{\mathrm{h}}}-r_{\mathrm{b}} \dot{\theta_{\mathrm{b}}}\right]+k_{2} \dot{y_{1}} r_{\mathrm{b}}=0 .
\end{aligned}
$$

For the matrix form of the motion equations, the following equations apply (Eqs. 10-13):

$$
\begin{aligned}
& M\{\ddot{q}\}=\left[\begin{array}{cccc}
m_{\mathrm{h}}+m_{\mathrm{f}}+m_{\mathrm{g}} & 0 & 0 & 0 \\
0 & m_{\mathrm{h}} r_{\mathrm{h}}^{2}+J_{\mathrm{ch}}+m_{\mathrm{f}} r_{\mathrm{h}}^{2}+J_{\mathrm{cf}}+m_{\mathrm{g}} r_{\mathrm{h}}^{2}+J_{\mathrm{cg}} & J_{\mathrm{cf}}+J_{\mathrm{cg}} & 0 \\
0 & J_{\mathrm{cf}}+J_{\mathrm{cgg}} & 0 \\
0 & 0 & 0 & J_{\mathrm{cb}}
\end{array}\right],
\end{aligned}
$$

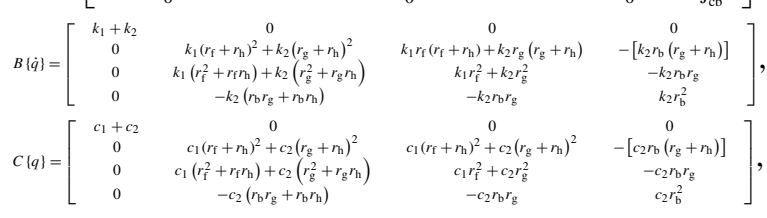

$$
\begin{aligned}
& \{D\}=\left[\begin{array}{c}
0 \\
M_{\mathrm{h}} \\
0 \\
0
\end{array}\right] \text {. }
\end{aligned}
$$

\section{Solutions of the dynamic motion equations}

The values of the basic input parameters of the model and reducers working characteristics are given in Table 1 . The geometric quantities, masses, and moments of inertia of certain planetary gear reducer elements are taken from the developed CAD model, while the stiffness and damping values are taken from the literature (Batinic, 2008, 2013).

In order to get the simulation model initiated, it was necessary to define an initiation torque on the input shaft which is directly connected to the carrier $\mathrm{h}$. The initiation torque function shape was obtained from literature (Batinic, 2008, 2013; Blagojević et al., 2018). The initiation torque graphic is shown in Fig. 3.
The dynamic motion equations are solved in the program MATLAB Simulink. Figure 4 shows acceleration diagrams for some directions, while Fig. 5 shows velocity diagrams.

Figure 6 shows displacement diagrams for certain directions, as the final results of this analysis.

\section{Discussion}

Oscillations of the analysed parameters are similar in form to the oscillation of the excitation torque, which is a periodic time function. The character of the displacement diagram is similar to the character of the velocity diagram. At first, oscillations of some parameters are very pronounced, but they calm down in time. The output degree of freedom on the gear $b$ has the highest oscillation. The explanation for this phenomenon is that gear b is the last one in the chain, and it gets all of the vibrations from the other elements. The model is well configured. This can be noted from differences between diagrams of acceleration, velocity, and movement. The oscillations for acceleration are very pronounced, while for the velocities they are calmed. For the movement diagram, the curve is smooth.

\section{Conclusions}

This paper presents the dynamic behaviour of a planetary reducer with two planet gears. A complex dynamic model of the planetary reducer is made using Lagrange's equations of the second kind. The equation system is developed for all the degrees of freedom which describe the dynamical behaviour of the reducer gear in a high level of detail. The equations are solved in the math simulation software. Geometric quantities, masses, and moments of inertia for some of the elements are taken from the developed CAD model, while the stiffness and damping values are taken from the literature.

Based on the performed simulations, it can be concluded that the size of oscillations primarily depends on the way the dynamic model is set and on the values of the stiffness and the damping coefficients. The form of oscillations mostly depends on the excitation torque. Oscillations of velocities generally have a similar form as oscillations of displacements.

Further studies may include theoretical, analytical, and experimental investigations. However, the dynamic model needs to be further developed, and the stiffness and damping should be more precisely determined. The best way forward for further research is to manufacture the reducer with the same characteristics and to perform experimental measurements for the described phenomena. 
Table 1. Basic parameters of the dynamical model.

\begin{tabular}{lll}
\hline Parameter & Notation & Value \\
\hline Input power & $P_{\mathrm{in}}$ & $5 \mathrm{~kW}$ \\
Input RPM & $n_{\mathrm{in}}$ & $1200 \mathrm{RPM}$ \\
Transmission ratio & $i$ & 20 \\
Reducer length & $l_{\mathrm{r}}$ & $660 \mathrm{~mm}$ \\
Reducer width & $w_{\mathrm{r}}$ & $320 \mathrm{~mm}$ \\
Reducer height & $h_{\mathrm{r}}$ & $400 \mathrm{~mm}$ \\
Mass of the planet gear carrier h & $m_{\mathrm{h}}$ & $11.152 \mathrm{~kg}$ \\
Mass of the gear f & $m_{\mathrm{f}}$ & $3.376 \mathrm{~kg}$ \\
Mass of the gear g & $m_{\mathrm{g}}$ & $8.563 \mathrm{~kg}$ \\
Moment of inertia of the planet gear carrier h & $J_{\mathrm{ch}}$ & $116.086 \times 10^{-3} \mathrm{~kg} \mathrm{~m}^{2}$ \\
Moment of inertia of the gear $\mathrm{f}$ & $J_{\mathrm{cf}}$ & $3.039 \times 10^{-3} \mathrm{~kg} \mathrm{~m}^{2}$ \\
Moment of inertia of the gear g & $J_{\mathrm{cg}}$ & $16.778 \times 10^{-3} \mathrm{~kg} \mathrm{~m}^{2}$ \\
Moment of inertia of the gear b & $J_{\mathrm{cb}}$ & $306.512 \times 10^{-3} \mathrm{~kg} \mathrm{~m}^{2}$ \\
Mutual distance & $r_{\mathrm{h}}$ & $69 \mathrm{~mm}$ \\
Radius of the pitch circle of the gear $\mathrm{f}$ & $r_{\mathrm{f}}$ & $52.5 \mathrm{~mm}$ \\
Radius of the pitch circle of the gear g & $r_{\mathrm{g}}$ & $48 \mathrm{~mm}$ \\
Radius of the pitch circle of the gear $\mathrm{b}$ & $r_{\mathrm{b}}$ & $117 \mathrm{~mm}$ \\
Mesh stiffness f-e & $c_{1}$ & $1.67 \times 10^{10} \mathrm{~N} \mathrm{~m}^{-1}$ \\
Mesh stiffness g-b & $c_{2}$ & $1.56 \times 10^{10} \mathrm{~N} \mathrm{~m}^{-1}$ \\
Mesh damping f-e & $k_{1}$ & $3200 \mathrm{~N} \mathrm{~s} \mathrm{~m}^{-1}$ \\
Mesh damping g-b & $k_{2}$ & $2400 \mathrm{~N} \mathrm{~m} \mathrm{~m}^{-1}$ \\
\hline
\end{tabular}

(a)

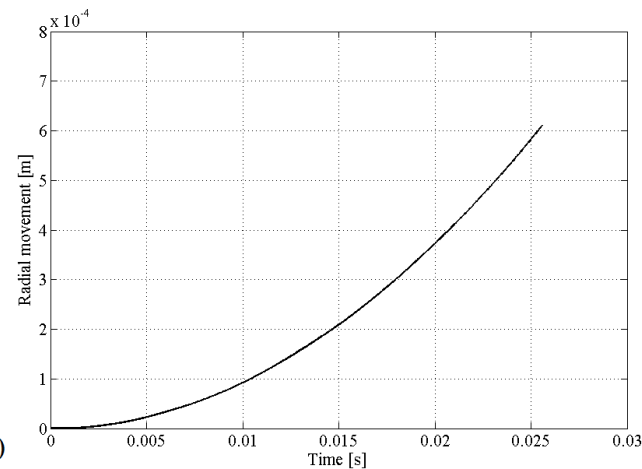

(c)

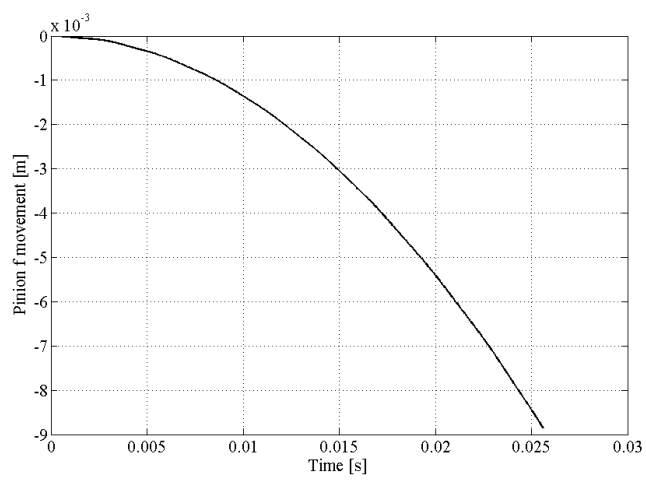

(b)
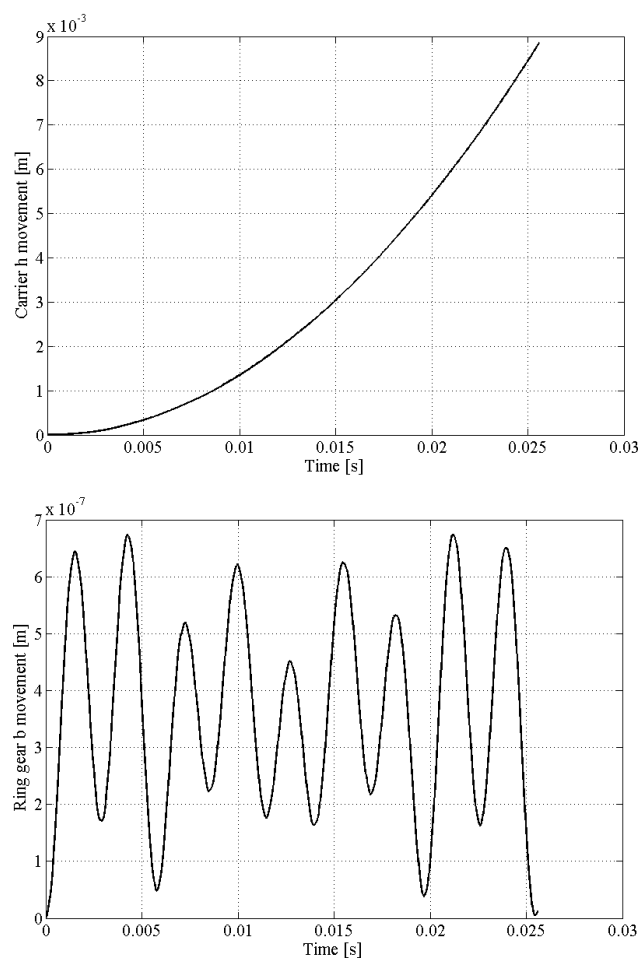

Figure 6. Displacement diagrams for $c_{1}=1.67 \times 10^{10} \mathrm{~N} \mathrm{~m}^{-1}, c_{2}=1.56 \times 10^{10} \mathrm{~N} \mathrm{~m}^{-1}, k_{1}=3200 \mathrm{~N} \mathrm{~s} \mathrm{~m}^{-1}$, and $k_{2}=2400 \mathrm{~N} \mathrm{~s} \mathrm{~m}^{-1}:\left(\right.$ a) $y_{1}$ direction, (b) $\theta_{\mathrm{h}}$ direction, (c) $\theta_{\mathrm{f}}$ direction, and (d) $\theta_{\mathrm{b}}$ direction. 
Code and data availability. Currently, all calculations performed in MATLAB R2017a and the program itself are stored locally. All data will be provided on request, however.

Author contributions. MM responsibility was to do calculations, simulations and figures production. MB took responsibility for the concept, supervision and initial review of the completed article. MM took responsibility for the review of the literature and writing the paper and doing the initial lecturing.

Competing interests. The contact author has declared that neither they nor their co-authors have any competing interests.

Disclaimer. Publisher's note: Copernicus Publications remains neutral with regard to jurisdictional claims in published maps and institutional affiliations.

Acknowledgements. This paper is a result of Project TR33015 of the Ministry of Education, Science and Technological Development in Serbia. The project is titled "Research and development of a Serbian zero-net energy house". We would like to thank the Ministry of Education, Science and Technological Development on its financial support during this research.

Financial support. This research has been supported by Ministry of Education, Science and Technological Development in Serbia (grant no. TR33015).

Review statement. This paper was edited by Daniel Condurache and reviewed by two anonymous referees.

\section{References}

Bahk, C. J. and Parker, R. G.: Analytical investigation of tooth profile modification effects on planetary gear dynamics, Mech. Mach. Theory, 70, 298-319, https://doi.org/10.1016/j.mechmachtheory.2013.07.018, 2013.

Bao, H., Jin, G., and Lu, F.: Nonlinear dynamic analysis of an external gear system with meshing beyond pitch point, J. Mech. Sci. Technol., 34, 4951-4963, https://doi.org/10.1007/s12206020-1101-8, 2020.

Batinic, V.: Planetary gear dynamic response to mesh parametric excitation, Vojnoteh. Glas., 61, 58-68, https://doi.org/10.5937/vojtehg61-2006, 2013.

Batinic, V.: Određivanje krutosti planetarnog prenosnika, Sci. Tech. Rev., 56, 227-236, 2008.
Blagojevic, M., Matejic, M., and Vasic, M.: Comparative Overview of Calculation of Normal Force on Cycloidal Gear Tooth, in: Internatioal Congress Motor Vehicles \& Motors - Conference porceedings, 131-137, 2020.

Blagojevic, M., Nikolic-Stanojevic, V., Marjanovic, N., and Veljovic, L.: Analysis of Cycloid Drive Dynamic Behavior, Sci. Tech. Rev., LIX, 52-56, 2009.

Blagojević, M., Matejić, M., and Kostić, N.: Dynamic behaviour of a two-stage cycloidal speed reducer of a new design concept, Teh. Vjesn., 25, 291-298, https://doi.org/10.17559/TV20160530144431, 2018.

$\mathrm{Bu}, \mathrm{Z} ., \mathrm{Liu}, \mathrm{G}$. , and Wu, L.: Modal analyses of herringbone planetary gear train with journal bearings, Mech. Mach. Theory, 54, 99-115, https://doi.org/10.1016/j.mechmachtheory.2012.03.006, 2012.

Chen, X., Yang, X., and Zuo, M. J.: Clearance and Sun Gear Tooth Crack †, 21, 2638, https://doi.org/10.3390/s21082638, 2021.

Chen, Z. and Shao, Y.: Dynamic simulation of planetary gear with tooth root crack in ring gear, Eng. Fail. Anal., 31, 8-18, https://doi.org/10.1016/j.engfailanal.2013.01.012, 2013.

$\mathrm{Gu}, \mathrm{X}$. and Velex, P.: On the dynamic simulation of eccentricity errors in planetary gears, Mech. Mach. Theory, 61, 14-29, https://doi.org/10.1016/j.mechmachtheory.2012.10.003, 2013.

Inalpolat, M. and Kahraman, A.: A dynamic model to predict modulation sidebands of a planetary gear set having manufacturing errors, J. Sound Vib., 329, 371-393, https://doi.org/10.1016/j.jsv.2009.09.022, 2010.

Kang, M. R. and Kahraman, A.: An experimental and theoretical study of the dynamic behavior of double-helical gear sets, J. Sound Vib., 350, 11-29, https://doi.org/10.1016/j.jsv.2015.04.008, 2015.

Karaivanov, D., Troha, S., and Pavlova, R.: Investigation into selflocking planetary gear trains through the lever analogy, Trans. Famena, 36, 13-24, 2012.

Luo, Y. and Di, T.: Dynamics modeling of planetary gear set considering meshing stiffness based on bond graph, Procedia Eng., 24, 850-855, https://doi.org/10.1016/j.proeng.2011.11.2749, 2011.

Shakeri Aski, F., Mirparizi, M., Sheykh Samani, F., and Ali Hajabasi, M.: Vibration behavior optimization of planetary gear sets, Propuls. Power Res., 3, 196-206, https://doi.org/10.1016/j.jppr.2014.11.002, 2014.

Sondkar, P. and Kahraman, A.: A dynamic model of a doublehelical planetary gear set, Mech. Mach. Theory, 70, 157-174, https://doi.org/10.1016/j.mechmachtheory.2013.07.005, 2013.

Troha, S., Lovrin, N., and Milovančević, M.: Selection of the twocarrier shifting Planetary Gear Train controlled by Clutches and Brakes, Trans. Famena, 36, 1-12, 2012.

Troha, S., Zigulić, R., and Karaivanov, D.: Kinematic operating modes of two-speed two-carrier planetary gear trains with four external shafts, Trans. Famena, 38, 63-76, 2014.

Zhang, L., Wang, Y., Wu, K., Sheng, R., and Huang, Q.: Dynamic modeling and vibration characteristics of a two-stage closedform planetary gear train, Mech. Mach. Theory, 97, 12-28, https://doi.org/10.1016/j.mechmachtheory.2015.10.006, 2016. 